\title{
PT4a Stage Finding
}

National Cancer Institute

\section{Source}

National Cancer Institute. pT4a Stage Finding. NCI Thesaurus. Code C48773.

A pathologic primary tumor TNM stage finding. The definition of pT 4a stage finding depends on the particular type of cancer that it refers to; for example, for breast cancer, PT 4a stage finding is defined as follows: cancer with extension to the chest wall, not including the pectoralis muscle; for thyroid cancer, pT 4a stage finding is defined as follows: cancer with moderately advanced local disease. T umor of any size extending beyond the thyroid gland capsule to invade subcutaneous soft tissues, larynx, trachea, esophagus, or recurrent laryngeal nerve. (from AJCC 7th Ed.) 